\title{
Endothelial-Specific Knockdown of Interleukin-1 (IL-1) Type 1 Receptor Differentially Alters CNS Responses to IL-1 Depending on Its Route of Administration
}

\author{
San Ching, ${ }^{1 *}$ Hao Zhang, ${ }^{1 *}$ Natalya Belevych, ${ }^{1}$ Lingli He, ${ }^{1}$ Wenmin Lai, ${ }^{1}$ Xin-an Pu, ${ }^{2}$ Laura B. Jaeger, ${ }^{3}$ Qun Chen, ${ }^{1}$ and \\ Ning Quan ${ }^{1}$ \\ ${ }^{1}$ Department of Oral Biology and ${ }^{2}$ Center for Neurobiology, Ohio State University, Columbus, Ohio 43210-1094, and ${ }^{3}$ Department of Pharmacology and \\ Physiology, St. Louis University, St. Louis, Missouri 63106
}

\begin{abstract}
Interleukin-1 (IL-1) has been implicated as a critical mediator of neuroimmune communication. In the brain, the functional receptor for IL-1, type 1 IL-1 receptor (IL-1R1), is localized primarily to the endothelial cells. In this study, we created an endothelial-specific IL-1R1 knockdown model to test the role of endothelial IL-1R1 in mediating the effects of IL-1. Neuronal activation in the hypothalamus was measured by c-fos expression in the paraventricular nucleus and the ventromedial preoptic area. In addition, two specific sickness symptoms, febrile response and reduction of locomotor activity, were studied. Intracerebroventricular injection of IL-1 induced leukocyte infiltration into the CNS, activation of hypothalamic neurons, fever, and reduced locomotor activity in normal mice. Endothelialspecific knockdown of IL-1R1 abrogated all these responses. Intraperitoneal injection of IL-1 also induced neuronal activation in the hypothalamus, fever, and reduced locomotor activity, without inducing leukocyte infiltration into the brain. Endothelial-specific knockdown of IL-1R1 suppressed intraperitoneal IL-1-induced fever, but not the induction of c-fos in hypothalamus. When IL-1 was given intravenously, endothelial knockdown of IL-1R1 abolished intravenous IL-1-induced CNS activation and the two monitored sickness symptoms. In addition, endothelial-specific knockdown of IL-1R1 blocked the induction of cyclooxygenase-2 expression induced by all three routes of IL-1 administration. These results show that the effects of intravenous and intracerebroventricular IL-1 are mediated by endothelial IL-1R1, whereas the effects of intraperitoneal IL-1 are partially dependent on endothelial IL-1R1.
\end{abstract}

Key words: cytokine; neuroimmune; blood- brain barrier; fever; locomotor activity; illness behavior

\section{Introduction}

Interleukin-1 (IL-1) is the prototypical signal molecule for neuroimmune communication. Discovery of the actions of this inflammatory cytokine in the CNS (Berkenbosch et al., 1987; Sapolsky et al., 1987) was a cornerstone to the establishment of neuroimmunology. A salient feature of IL-1 function is that the actions of this molecule both in the periphery and in the CNS induce appropriate immunological, neuroendocrine, and behavioral responses, which are in concordance with those typically observed during acute infection (for review, see Quan and Herkenham, 2002). In vitro studies showed that IL-1 can act on cultured neurons (Akaneya et al., 1995), astrocytes (Das and Potter, 1995), and microglia (Li et al., 2003). Studies by in situ hybridization and immunohistochemistry, however, showed that expression of the functional IL-1 receptor (IL-1R1) is limited mostly to cells of the endothelium and in neurons in a few specific structures of the brain such as the basolateral nucleus of the

\footnotetext{
Received 0ct. 6, 2006; revised Aug. 8, 2007; accepted Aug. 9, 2007.

This work was supported by National Institutes of Health Grant R01 Al059089 (N.Q.).

*S.C. and H.Z. contributed equally to this work.

Correspondence should be addressed to Ning Quan, 4179 Postle Hall, 305 West 12th Avenue, Columbus, $\mathrm{OH}$ 43210-1094. E-mail: quan.14@osu.edu.

DOI:10.1523/JNEUROSCI.3357-07.2007

Copyright $\odot 2007$ Society for Neuroscience $\quad 0270-6474 / 07 / 2710476-11 \$ 15.00 / 0$
}

amygdala, the arcuate nucleus of the hypothalamus, the trigeminal and hypoglossal motornuclei, and the area postrema (Cunningham and De Souza, 1993; Ericsson et al., 1995; Konsman et al., 2004). Thus, the actions of IL-1 in the CNS may be mediated by endothelial cells or by the activation of neurons in the few specific brain structures bearing IL-1R1. The activities of neurons bearing neuronal IL-1R1 have been shown to be involved in the function of learning and memory (Lynch, 2002). Cells that express IL-1R1 mRNA and the neurons in the CNS activated by peripheral inflammation, however, do not colocalize (Ericsson et al., 1995).

Administration of IL-1, instead of globally stimulating the brain, as would be predicted by its interaction with widespread IL-1R1 on endothelial cells, induces activation of neurons in selected nuclei (Brady et al., 1994). Current explanation for this is that IL-1 induces an intermediate, prostaglandin $\mathrm{E}_{2}$, which then stimulates neurons bearing specific prostaglandin receptors in specific regions of the brain, thereby activating neurons in a selective manner (Zhang and Rivest, 2000). The following findings support this theory: (1) Peripheral immune challenge or central administration of IL-1 induces the expression of cyclooxygenase-2 (Cox-2) (Breder and Saper, 1996; Quan et al., 1998; Schiltz and Sawchenko, 2002), which is the inducible speed-limiting enzyme for prostaglandin synthesis. (2) Expres- 
sion of Cox-2 induced by peripheral immune challenge or central administration of IL-1 can be located in endothelial cells of the brain (Quan et al., 2003). (3) The levels of expression of endothelial Cox-2 correlated with the degree of CNS-controlled activity induced by peripheral immune stimulation (Cao et al., 1996). (4) Blockade of Cox-2 activity inhibits neuronal activation induced by peripheral immune challenges (Quan et al., 2003). Heretofore, it has been difficult to directly test the role of endothelial IL-1R1 in vivo because there is no animal model with which endothelial IL-1R1 (eIL-1R1) may be selectively blocked. In this study, we report the creation of a transgenic model using the tet-on system to specifically knockdown endothelial IL-1R1 expression. The effects of endothelial-specific blockade of IL-1R1 were directly tested.

\section{Materials and Methods}

\section{Cloning of transgenic constructs}

Driver construct. A plasmid containing Tie-2 promoter (2 kb)-lacZ-Tie2 enhancer $(10 \mathrm{~kb})$ (Tie-2-lacZ) was kindly provided by Dr. Tom Sato (Department of Internal Medicine and Molecular Biology, University of Texas Southwestern Medical Center, Dallas, TX). Transgenic animals made from this construct showed expression of LacZ in all endothelial cells (Schlaeger et al., 1997). PCR primers (forward primer: 5' -CGTTAATTAACTCCGACCTGCAGGAATTA; reverse primer: 5'-ATGGCGCGCCATCTGCTCTAGTAAGT) were designed to anneal to the Tie-2lacZ plasmid flanking the lacZ sequence. PacI and Ascl sites were included in the $5^{\prime}$ end of forward and reverse primers, respectively. Longdistance PCR was performed using these pair of primers and Tie-2-lacZ vector as the template. The resulting PCR product is a linear Tie-2-lacZ sequence minus the lacZ sequence $\left(\right.$ Tie-2-lac $Z^{-}$). This product was cloned into a TA cloning vector for propagation and subsequent digestion with $P a c$ I and $A s c 1$ in preparation for a later ligation. Plasmid containing the reverse tetracycline transactivator (rtTA) gene was purchased from Clontech (K1621-A; Clontech, Mountain View, CA). The open reading frame of the rtTA was generated by PCR amplification of this plasmid using the following pair of primers: 5 '-CCCGGCGCGCCAATTCATATGTCTA-3' (forward primer); and 5'-AAATTAATTAATATATCCAGTGATT-3' (reverse primer). An Asc1 and a PacI site were included in the $5^{\prime}$ end of the forward and reverse primers, respectively, to facilitate cloning of rtTA into the Tie-2-lacZ ${ }^{-}$vector, thereby inserting rtTA between the Tie- 2 promoter and Tie- 2 enhancer. To remove SalI site from this gene, site-directed mutagenesis of rtTA was performed on the rtTA vector using the QuikChange Site-Directed $\mathrm{Mu}-$ tagenesis kit (200519; Stratagene, La Jolla, CA) before proceeding to manipulate the rtTA fragment. The reason for this is that the SalI sites flanking the transgenic construct in the vector sequence will be used to excise the transgene from the vector, and this mutation prevents SalI from cutting the rtTA gene. Sequencing the modified rtTA showed that nucleotide $\mathrm{G}$ at position 1541 of the plasmid K1621 was changed to an A. This change did not alter the amino acids produced from this codon (both the original UCG and modified UCA code for serine). The modified rtTA open reading frame was then PCR amplified, again with PacI and $A s c 1$ sites included in the $5^{\prime}$ end of the primers. After PacI and Asc1 digest of the PCR product, rtTA was ligated to Tie-2-LacZ ${ }^{-}$to produce Tie-2-promoter-rtTA-enhancer $(10 \mathrm{~kb})$. This construct was designated as the driver (see Fig. 1).

Responder construct. A bidirectional tetracycline responsive responder (TRE) plasmid, pBi-EGFP (6154-1; Clontech), was purchased from Clontech. IL-1R1 cDNA was generated from reverse transcription of total RNA from brain RNA extract and PCR amplification with the following primers: 5'-ATATACGCGTGATGTCATCAGAGTTCCCAGTGC-3' (forward primer) and 5'-ATATACGCGTTTATGATGGGAGATATTCCGAAGT-3' (reverse primer). These primers flank the open reading frame of the IL-1R1 (GenBank accession no. NM_008362; nucleotides 181-2004) and contained MluI sites to the $5^{\prime}$ ends of both forward and reverse primers to facilitate cloning of the IL-1R1 cDNA into the MluI site in pBi-EGFP. After digestion of the PCR product with MluI, the $1.8 \mathrm{~kb}$ IL-1R1 cDNA fragment was ligated into the MluI site of the
pBi-EGFP vector. The resulting clones were screened for the insertion of IL-1R1 into the vector in the antisense direction by restriction-digest mapping and sequencing. The clone with correct antisense insertion of IL-1R1 was selected and designated as the responder (see Fig. 1). The driver and the responder constructs were excised from the vector plasmid with SalI and AseI, respectively, for injection into fertilized eggs.

\section{Generation of transgenic lines}

The driver and responder constructs were coinjected into fertilized eggs (FVB zygotes) at 3:1, 1:1, and 1:3 molar ratios. Transgenic animals were genotyped using tail DNA for the presence of rtTA (present in the driver) and enhanced green fluorescent protein (EGFP) (present in the responder) by PCR. The following primer sets were used for reverse transcription (RT)-PCR detection of these transgenes. Forward primer, $5^{\prime}$ GGGCGATGCCACCTACGGCAAGCGACCCT, and reverse primer, 5'-CCGTCCTCCTTGAAGTCGATGCCCTTCAGC, were used to detect EGFP; forward primer, 5' -CGCTGTGGGGCATTTTACTTTAG, and reverse primer, 5'-CATGTCCAGATCGAAATCGTC, were used to detect rtTA. The predicted correct amplicon sizes were 296 and $476 \mathrm{bp}$ for rtTA and EGFP, respectively. The PCR products were analyzed by electrophoresis with the Agilent 2100 Bioanalyzer (Agilent Technologies, Cary, NC).

To quantitatively detect mRNA expression of the transgenes, total RNA was isolated from mouse tails followed by generation of cDNA by reverse transcription. The cDNAs were analyzed by real-time PCR. Animals carrying both transgenes were fed either with water or with doxycycline (Dox) ( $2 \mathrm{mg} / \mathrm{ml}$; Sigma, St. Louis, MO) in their drinking water for at least $7 \mathrm{~d}$ before examination. The following primer-probe sets for real-time PCR analysis of rtTA and EGFP were used. For EGFP, 5'TGCTTGTCGGCCATGATATA was the forward primer, 5'-GAGCTGAAGGCCATCGACTT was the reverse primer, and the fluorescence probe was 6-carboxyfluorescein (FAM)-5'-TAGTTGTACTCCAGCTTGTGCCCCAGG-5-(and 6)-carboxytetramethylrhodamine (TAMRA). For rtTA, the forward primer was 5'-GCCCAGAAGCTTGGTGTAGAG, the reverse primer was $5^{\prime}$-TGGTGCCTATCTAACATCTCAATG, and the fluorescence probe was FAM-5'-CGCGTTATATGCACTCAGCGCT-TAMRA. The mRNA of the housekeeping gene G3PDH was measured as an internal control. The primer-probe set for this control was purchased from Applied Biosystems (Foster City, CA). Functional founders were identified by the induction of EGFP mRNA expression and the appearance of green fluorescence in the blood vessels after Dox treatment.

Two functional lines were identified of 53 founder animals. One of these lines was stable for several generations and demonstrated consistent desired phenotypic responses. This line was used in this study and referred to as the eIL-1R1 mouse.

Endothelial-specific IL-1R1 knockdown in transgenic animals was further verified by examination of whether the expression of IL-1R1 protein in brain blood vessels and in circulating leukocytes can be blocked by Dox treatment.

\section{Injection of $I L-1$}

For intracerebroventricular injection, eIL-1R1 mice and their nontransgenic littermates, weighing $20-30 \mathrm{~g}$ at the age of 6-10 weeks, were used. They were anesthetized by intraperitoneal injection of $2 \mathrm{mg} / 20 \mathrm{~g} \mathrm{Nem}-$ butal (Abbott Laboratories, North Chicago, IL) and then securely fixed onto the small animal stereotaxic (David Kopf Instrument, Tujunga, CA). A 28 gauge guide cannula was then inserted into the lateral ventricle (lateral from midline, $1 \mathrm{~mm}$; posterior to bregma, $0.7 \mathrm{~mm}$; ventral from the skull, $2.7 \mathrm{~mm}$ ) and secured on the skull with a glass polyalkenoate cement and sealed with a dummy injector (Plastic One, Roanoke, VA). After the animals recovered from the surgery for $2 \mathrm{~d}$, murine IL- $1 \beta$ ( $20 \mathrm{ng}$ in $10 \mu \mathrm{l}$; PeproTech, Rocky Hill, NJ) or saline was injected into the lateral ventricle. The precision of this procedure was verified by examining the injection site using trypan blue. For intraperitoneal injection of IL-1, recombinant murine IL- $1 \beta$ dissolved in pyrogen-free saline was injected intraperitoneally into each mouse. The dose of the IL-1 was $20 \mu \mathrm{g} / \mathrm{kg}$ in $500 \mu \mathrm{l}$ of PBS. For intravenous injection of IL-1, mice were fixed in a rotating tail injector (Braintree Scientific, Braintree, MA) and 30 or 3 
$\mu \mathrm{g} / \mathrm{kg}$ of IL- $1 \beta$ in $100 \mu \mathrm{l}$ of PBS was injected into the tail vein using a sterile 30G1/2 needle. The doses of IL-1 were chosen from studies in the literature that showed these doses of IL-1 effectively induce neuroimmune effects (Brady et al., 1994; Proescholdt et al., 2002). For Doxtreated animals, animals were always treated with Dox for $7 \mathrm{~d}$. IL-1 was then injected on the last day of the Dox treatment.

\section{Immunohistochemical detection of IL-1R1, Cox-2, and CD45}

Animals were killed by decapitation. The fresh-frozen brains were then cryostat-cut to $20-\mu \mathrm{m}$-thick coronal sections. The sections were fixed in an acetone/alcohol mixture (3:1) for $5 \mathrm{~min}$. The sections were treated with glucose oxidase and sodium azide to reduce background interference. The sections were then incubated with anti-IL-1R1 (1:1000; rat anti-murine IL-1R1; BD Biosciences, Franklin Lakes, NJ) overnight and visualized by biotin-labeled secondary antibody with signal amplification (GenPoint Amplified Detection System; DakoCytomation, High Wycombe, UK). For detection of Cox-2 and CD45, the sections were incubated with a goat anti-Cox-2 antibody (1:200; sc-1747; Santa Cruz Biotechnology, Santa Cruz, CA) or anti-CD45 (1:100; BD Biosciences, Franklin Lakes, NJ). The labeling was visualized by subsequent binding of appropriate secondary antibodies (1:200) followed by streptavidin/ HRP (1:500/1:2500), or streptavidin-Cy2 (1:400). To exclude nonspecific labeling by these antibodies, we performed immunohistochemical (IHC) labeling of these antibodies on sections collected from IL-1R1 and Cox-2 knock-out animals.

In-cell Western blot analysis of IL-1R1 in leukocytes

Whole blood collected from mice was diluted in heparinized saline. The blood samples were slowly layered onto Histopaque-1077 (Sigma) in a 15 $\mathrm{ml}$ centrifuge tube. After centrifugation at $400 \times \mathrm{g}$ for $30 \mathrm{~min}$ at room temperature, the resulting interface layer containing leukocytes was carefully collected. The isolated leukocytes were washed twice with $10 \mathrm{ml}$ of wash buffer $\left(1 \% \mathrm{BSA} / \mathrm{PBS}\right.$ with $\left.0.05 \% \mathrm{NaN}_{3}\right)$ and centrifuged at $250 \times g$ for $10 \mathrm{~min}$ at room temperature. Cell pellets were then suspended in $1 \mathrm{ml}$ of wash buffer and cell number was adjusted to $2 \times 10^{6}$ per milliliter. The leukocytes were then fixed in $1 \%$ paraformaldehyde on ice for $30 \mathrm{~min}$. A total of $100 \mu \mathrm{l}$ of the fixed leukocytes suspension was incubated with a specific antibody for IL-1R1 (rabbit anti-mouse IL-1R1; Santa Cruz Biotechnology) in 1:200 dilution on ice for $30 \mathrm{~min}$. The samples were then washed and incubated with an infrared dye (IRdye $800 \mathrm{CW}$ )-labeled goat anti-rabbit antibody (LI-COR Biosciences, Lincoln, NE) in 1:8000 dilution. The samples were detected by Odyssey Infrared Imaging System (LI-COR Biosciences). The strength of the signal is reported as the integrated intensity.

Detection of c-fos mRNA by in situ hybridization histochemistry The in situ hybridization histochemistry (ISHH) labeling protocols was performed as described previously by us for digoxygenin-labeled ribonucleotide (cRNA) probes. Briefly, fresh-frozen brain sections were processed by fixation with $4 \%$ formaldehyde solution, acetylation with $0.25 \%$ acetic anhydride in $0.1 \mathrm{~m}$ triethanolamine $-\mathrm{HCl}, \mathrm{pH} 8.0$, solution, dehydration with ethanol, and delipidation with chloroform. Then, antisense c-fos was transcribed using the Roboprobe System (Promega, Madison, WI) with T7 RNA polymerase and digoxygenin-labeled UTP. After overnight incubation of the sections with the probes at $55^{\circ} \mathrm{C}$ in a humidified chamber, slides containing brain sections were washed first in $20 \mu \mathrm{g} / \mathrm{ml}$ RNase solution and then in $2 \times$ SSC and $0.2 \times$ SSC at $(55$ and $60^{\circ} \mathrm{C}$ ) solutions to reduce nonspecific binding of the probe. The sections were then stained with an anti-dig antibody (DakoCytomation) and visualized with Cy-2 streptavidin.

\section{Cell count}

Results of IHC and ISHH labeling were photographed using a digital camera (MTI 3CCD) connected to the microscope. The pictures were taken from coronal sections between bregma 0.50 and $0.26 \mathrm{~mm}$ for ventromedial preoptic area (VMPO) and between bregma -0.70 and -0.94 $\mathrm{mm}$ for paraventricular nucleus (PVN). A rectangular area of $1536 \times$ 1151 pixels image taken from the digital camera at $400 \times$ magnification was used as the standard counting field. The numbers of stained cells were counted from the entire field of these pictures.

\section{\begin{tabular}{l|l|l|l|}
\hline Driver Tie-2 Promoter(2kb) & rTA & PA & Tie-2 ehancer(10kb) \\
\hline
\end{tabular}}

\begin{tabular}{l||l|l|} 
Responder & EGFP & Antisense IL-1R1 \\
\hline
\end{tabular}

Figure 1. Schematic drawings of the driver and the responder transgene constructs. In the driver construct, rtTA with an SV40 poly(A) sequence (PA) was inserted between the Tie-2 promoter and the Tie-2 enhancer initially generated by Dr. Tom Sato's group (Schlaeger et al., 1997). In the responder construct, the bidirectional TRE was flanked by EGFP and antisense IL-1R1.

\section{Double-label IHC}

To identify the cell type of IL-1R1-, Cox-2-, and EGFP-expressing cells, double-label IHC was performed. For double labeling of IL-1R1 and platelet/endothelial cell adhesion molecule (PECAM) (an endothelial marker), anti-IL-1R1 was used as the primary antibody at a 1:1000 dilution. Anti-rat IgG was then used at a 1:200 dilution for $1 \mathrm{~h}$ at room temperature. This labeling was amplified with the GenPoint amplification kit and visualized with Cy3-streptavidin (1:800). The sections were then stained by the second labeling antibody, anti-PECAM (sc-1506; Santa Cruz Biotechnology). This time the reaction was visualized with Cy-2 streptavidin. Similarly, brain sections were first stained by antiCox-2 as described above, or anti-GFP (ab290; Abcam, Cambridge, MA), visualized with $\mathrm{Cy}-2$ streptavidin. Then, the sections were stained by anti-PECAM and visualized with Cy-3 streptavidin. Results were examined by a fluorescent microscope (BX51; Olympus, Melville, NY).

\section{Measurement of body temperature and locomotor activity by telemetry}

Mice were anesthetized by intraperitoneal injection of $2 \mathrm{mg} / 20 \mathrm{~g}$ Nembutal. A PDT-4000 E-mitter (Mini Mitter, Bend, OR) was surgically placed in the peritoneal cavity. The mice were administered $500 \mathrm{U}$ of penicillin intramuscularly after surgery. They were allowed $6 \mathrm{~d}$ to recover before experimentation. The ambient temperature during experimentation was $26 \pm 2^{\circ} \mathrm{C}$. Signals were calibrated to degree Celsius (for temperature) or to counts per minute (for locomotor activity) by the manufacturer using the software VitalView (Data Acquisition System; Mini Mitter). Data for temperature and activity were averaged over $10 \mathrm{~min}$ intervals to obtain the average value for every $10 \mathrm{~min}$ period of a given experiment. The animals were recorded for a week before the actual recording in an experiment. The body temperature and activity patterns were stabilized after this period of acclimation and display repeated daily rhythms.

Functional transgenic animals that were fed with water were designated as eIL-1R1-water animals. Functional transgenic mice treated with Dox were designated as eIL-1R1-Dox animals. The control animals were littermates of the transgenic animals that did not carry the transgenes. All experiments were conducted in accordance with the National Institutes of Health's guidelines on the care and use of animals for research and an in-house protocol approved by the Ohio State University Animal Care and Use Committee.

\section{Statistical analysis}

Baseline body temperature and locomotor activity were determined for each animal using mean values for the $2 \mathrm{~d}$ before IL- 1 injection. Temperatures and activity counts were analyzed for the $12 \mathrm{~h}$ after IL- 1 injection across all time points using a repeated-measures ANOVA to assess the amplitude of fever and reduction in activity. Post hoc differences between all means were analyzed using Dunnett's test. All tests were considered significant if $p<0.05$.

\section{Results}

Figure 1 shows the two constructs made in this study for the generation of conditional endothelial IL-1R1 knockdown animals. In the first construct (driver), rtTA plus simian virus 40 (SV40) polyadenylation sequence was inserted between the promoter and the enhancer of Tie-2 gene (an endothelial-specific gene). In the second construct (responder), EGFP and antisense 

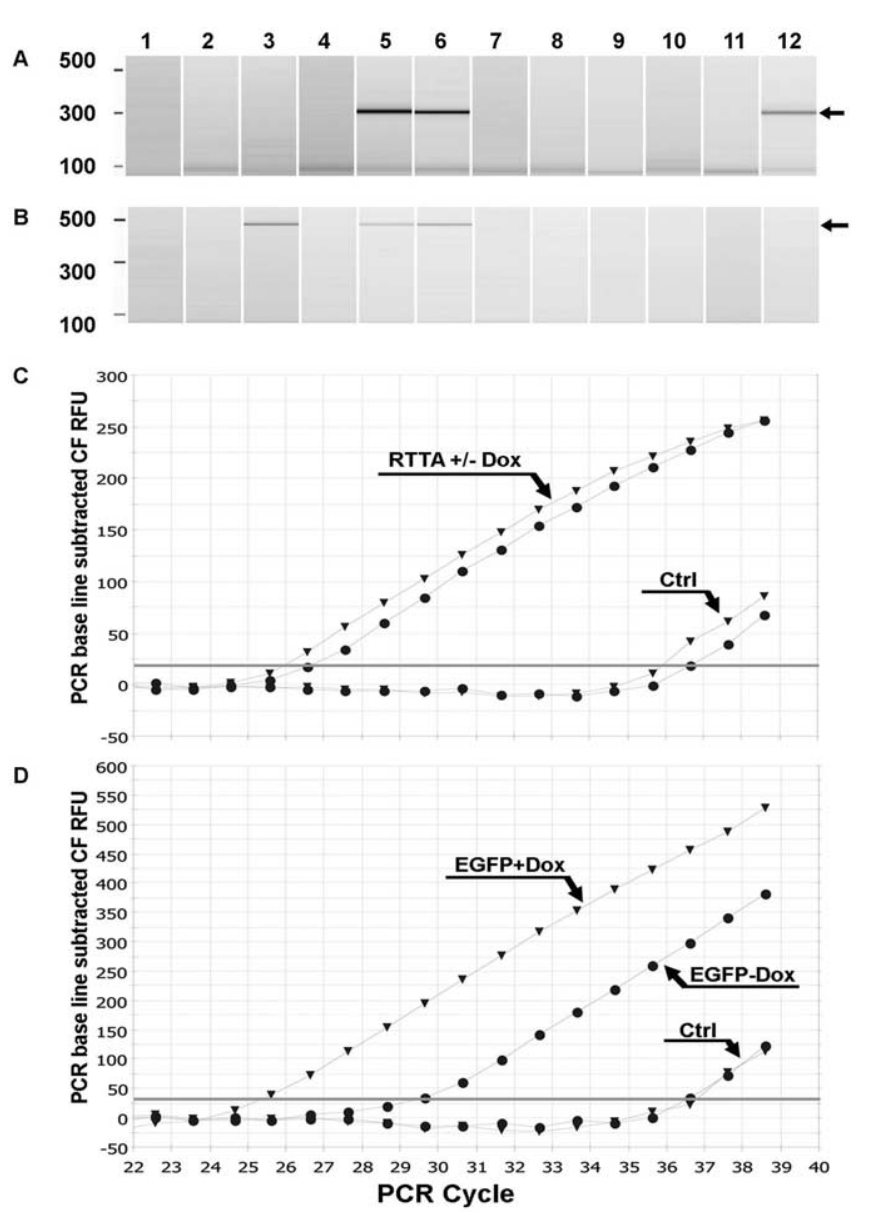

Figure 2. Identification of elL-1R1 founder animal. $\boldsymbol{A}$, Examples of $\mathrm{PCR}$ results from testing the presence of rtTA in genomic DNA in a litter of potential transgenic mice. Animals 5, 6, and 12 are shown to have acquired the driver rtTA gene (the arrow points to the predicted amplicon size). $B, P C$ R results from testing the presence of EGFP in genomic DNA in the same litter of mice. Animals 3, 5, and 6 contained the responder EGFP gene (the arrow points to the predicted amplicon size). The mRNA expressions of these genes from animal 6 were further tested by real-time $P C R$ and are presented in $\boldsymbol{C}(\mathrm{rtTA})$ and $\boldsymbol{D}$ (EGFP). The mRNA for rtTA was expressed in this animal with and without Dox treatment ( + Dox and - Dox). No CDNA was detected in the control samples generated from the same mRNA sample without reverse transcription (Ctrl lines in $\boldsymbol{C}$ and $\boldsymbol{D}$; the threshold detection level by our real-time $P C R$ is 31 cycles). Dox treatment dramatically increased the expression of EGFP compared with that detected in this animal without Dox treatment. Animal 6 and its offspring carrying both transgenes are designated as the elL-1R1 mice.

IL-1R1 were ligated to a bidirectional tetracycline responsive element construct (Bi-TRE). These construct sequences were verified by sequencing.

Figure 2 shows the identification of the functional transgenic animals carrying both transgenes. Figure 2, $A$ and $B$, shows examples of tail DNA PCR results from a litter of 12 potential transgenic animals. PCR products for rtTA are shown in Figure $2 \mathrm{~A}$, and PCR products for EGFP are shown in Figure $2 B$. Animals 5, 6 , and 12 contained the driver rtTA gene. Animals 3, 5, and 6 contained the responder EGFP gene. Because animals 5 and 6 contained both transgenes, we further tested the expression of these genes. Figure 2, $C$ and $D$, shows the real-time RT-PCR results obtained from animal 6 . Tail RNA expression for rtTA was found in this animal with (+Dox) or without Dox ( - Dox $)$ treatment (Fig. 2C). Dox treatment did not induce increased expression of the rtTA. RNAs from tail tissues without reverse transcription were used as controls (Ctrl). No PCR amplification was detected in these control samples. Thus, the driver gene was constitutively expressed in animal 6 and its expression was unaltered by Dox treatment. Expression of EGFP mRNA was also detected in the tail tissue of this animal (Fig. 2D). Dox treatment (+Dox) dramatically increased the expression of EGFP compared with the level of this gene detected in this animal without Dox treatment (-Dox). Figure 2, $C$ and $D$, is representative of three separate experiments on animal 6 . This animal was subsequently used as our founder animal. Other animals, such as animal 5 in this litter did not express the EGFP mRNA (data not shown). In all the subsequent studies, only the offspring of animal 6 that carried both transgenes were used. They were designated as the eIL-1R1 mice.

Figure 3 shows representative fluorescence microphotographs taken from the brain sections of control nontransgenic $(A)$, eIL1R1-water (eIL-1R1 mice fed with water $(B)$, and eIL-1R1-Dox (eIL-1R1 mice fed with Dox) $(C)$ animals. The cellular green fluorescence traces the expression of EGFP. No green fluorescence was found in control nontransgenic mice (Fig. 3A). EGFP expression was visualized in all the blood vessels of the brain in eIL-1R1-Dox mice (Fig. 3C). The EGFP-expressing cells can be identified as endothelial cells from double-labeling of the EGFP molecule and the endothelial marker PECAM (Fig. 3C, inset). In eIL-1R1-water animals (Fig. 3B), sparse and weak expression of EGFP on large blood vessels was observed (Fig. 3B, arrow), suggesting that there was a small amount of leaky transcription of EGFP in these animals without stimulation by Dox. These results are consistent with the phenotype of the founder mouse that showed weak expression of EGFP without Dox treatment, but strong expression of EGFP after Dox treatment. Thus, although the bitransgenic animals exhibit weak leaky transcription in sparse blood vessel cells, Dox treatment results in activation of the responder genes in all endothelial cells.

We then analyzed whether IL-1R1 expression in leukocytes was suppressed in eIL-1R1 animals. Figure 4 shows results from in-cell Western analysis of IL-1R1 expression on leukocytes. IL$1 \mathrm{R} 1$ was detected in normal nontransgenic animals as well as eIL-1R1-water and eIL-1R1-Dox animals. No change of IL-1R1 levels was detected in these cells. No IL-1R1, however, was detected in leukocytes collected from IL-1R1 knock-out animals (data not shown), demonstrating that this method specifically detected the presence of IL-1R1. These results show that eIL-1R1Dox did not block IL-1R1 expression in leukocytes.

Figure 5 shows representative microphotographs of IHC labeling of IL-1R1 and ISSH labeling of c-fos in the brain tissue. Pictures from paraventricular nucleus of the hypothalamus (PVN) are shown. No IL-1R1 labeling was detected in IL-1R1 knock-out animals (Fig. 5A). In control nontransgenic animals, IL-1R1 was labeled in the blood vessels of the hypothalamus. This was accentuated at PVN because this nucleus is known to be populated by higher levels of vasculature (Fig. 5B) (dashed lines in Fig. 5 indicate the boundary of PVN proper). Two hours after intracerebroventricular IL-1 injection, IL-1R1 expression did not change in these animals (Fig. 5C). In eIL-1R1-water animals, neither saline (Fig. 5D) nor IL-1 (Fig. 5E) injection induced significant change in IL-1R1 levels. Double-labeling with anti-IL1R1 (red) and anti-PECAM (red) showed that IL-1R1 in the PVN is expressed on endothelial cells (Fig. 5E, inset). In eIL-1R1-Dox animals, the expression of IL-1R1 was absent after either saline (data not shown) or IL-1 injection (Fig. 5F).

After saline injection, the mRNA expression of c-fos was not observed in nontransgenic control (Fig. 5b), eIL-1R1-water (Fig. $5 d$ ), and eIL-1R1-Dox (data not shown) animals. After intrace- 

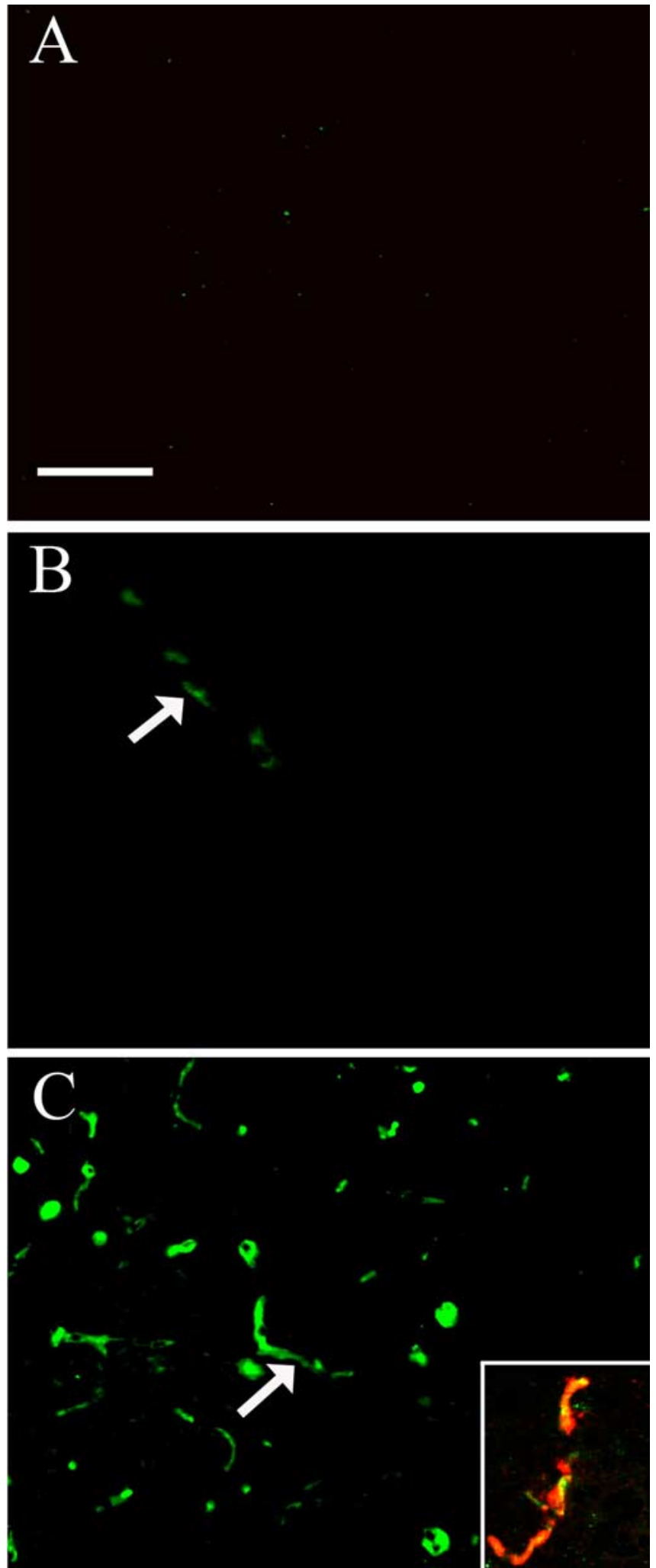

Figure 3. Representative microphotographs showing EGFP expression in the brain. $\boldsymbol{A}$, № green fluorescence was found in nontransgenic animals. $\boldsymbol{B}$, In ell-1R1 animals that received no Dox in their drinking water (ell-1R1-water), only sparse and weak green fluorescence on blood vessels were found (arrow). $C$, In elL-1R1 animals that were fed with Dox (ell-1R1-Dox) for at least $7 \mathrm{~d}$, uniform and universal expression of EGFP was seen in endothelial cells of all the blood vessels in the brain. The inset in C shows a high-magnification photograph of a cell double labeled by anti-EGFP and anti-PECAM. Scale bar, $100 \mu \mathrm{m}$.

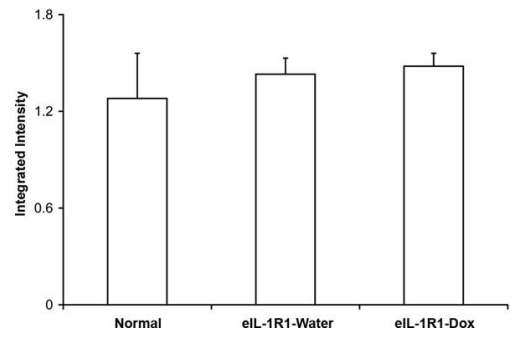

Figure 4. In-cell Western measurement of IL-1R1 expression in leukocytes of normal, ell1R1-water, and elL-1R1-Dox animals. IL-1R1 was detected in leukocytes of all of these animals without significant difference. Mean \pm SE are shown ( $n=5$ /group).

rebroventricular IL-1 injection, c-fos mRNA was found in the PVN of nontransgenic (Fig. 5c) and eIL-1R1-water (Fig. 5e) animals, but not in eIL-1R1-Dox (Fig. $5 f$ ) and IL-1R1 knock-out (Fig. 5a) animals.

Quantitative analyses of c-fos-expressing cells in PVN as well as those in the VMPO after intracerebroventricular IL-1 injection are shown in Figure 6. Significant increase of c-fos-labeled cells were found in both PVN (Fig. 6A) and VMPO (Fig. 6B; inset in this figure show the region of quantitative analysis) after intracerebroventricular IL-1 injection in control nontransgenic and in eIL-1R1-water animals. Induction of c-fos expression was blunted in eIL-1R1-Dox animals.

Next, we examined the induction of leukocyte infiltration into the brain induced by intracerebroventricular IL-1. Induction of leukocyte infiltration into brain parenchyma is one of the characteristic activities of endothelium-mediated brain IL-1 function. Figure 7, $A-D$, shows representative microphotographs of CD45 labeling in brain parenchyma induced by intracerebroventricular IL-1 injection $16 \mathrm{~h}$ after injection. No CD45 ${ }^{+}$cells were found in saline-injected normal brain (Fig. 7A). In both normal (Fig. 7B) and eIL-1R1-water animals (Fig. 7C), IL-1 injection induced widespread appearance of $\mathrm{CD}_{4} 5^{+}$cells in the brain parenchyma. Figure 7, inset, shows a high magnification photograph of $\mathrm{CD} 45^{+}$cells with the morphology of infiltrating leukocytes. In eIL-1R1-Dox animals (Fig. 7D), however, the infiltration of $\mathrm{CD} 45^{+}$cells in the brain parenchyma was absent, although $\mathrm{CD}_{4}{ }^{+}$cells were found in the cerebral ventricles (data not shown). Quantitative analysis of number of $\mathrm{CD} 45^{+}$cells in brain parenchyma after intracerebroventricular injection of saline and IL-1 is shown in Figure 7E. Note that the number of infiltrating leukocytes induced in this study ( $26 \pm 5$ per field) is not different from that ( $21 \pm 3$ per field) reported in a previous study (Ching et al., 2005) in which IL-1 was injected intracerebroventricular without implantation of a guide cannula. Therefore, surgical damage to the blood-brain barrier in the present study (restricted to a very small brain region) did not influence the outcome of IL-1-induced leukocyte infiltration. IL-1-induced leukocyte infiltration was essentially blocked in eIL-1R1-Dox animals (Fig. 7E) in the present study.

Figure 8 shows changes in body temperature and locomotor activity after intracerebroventricular injection of IL-1 at 10:00 A.M. In free-moving saline-injected eIL-1R1-water animals, body temperature fluctuated with the amount of locomotor activity of the animals. There is a daytime decline of body temperature to about $-0.8^{\circ} \mathrm{C}$ below morning temperature. After intracerebroventricular injection of IL-1, body temperature was elevated above those observed in saline-injected animals, beginning at $2 \mathrm{~h}$ after the injection (Fig. $8 \mathrm{~A}$ ). The increase of body temperature persisted until $8 \mathrm{~h}$ after the injection. From 7:00 

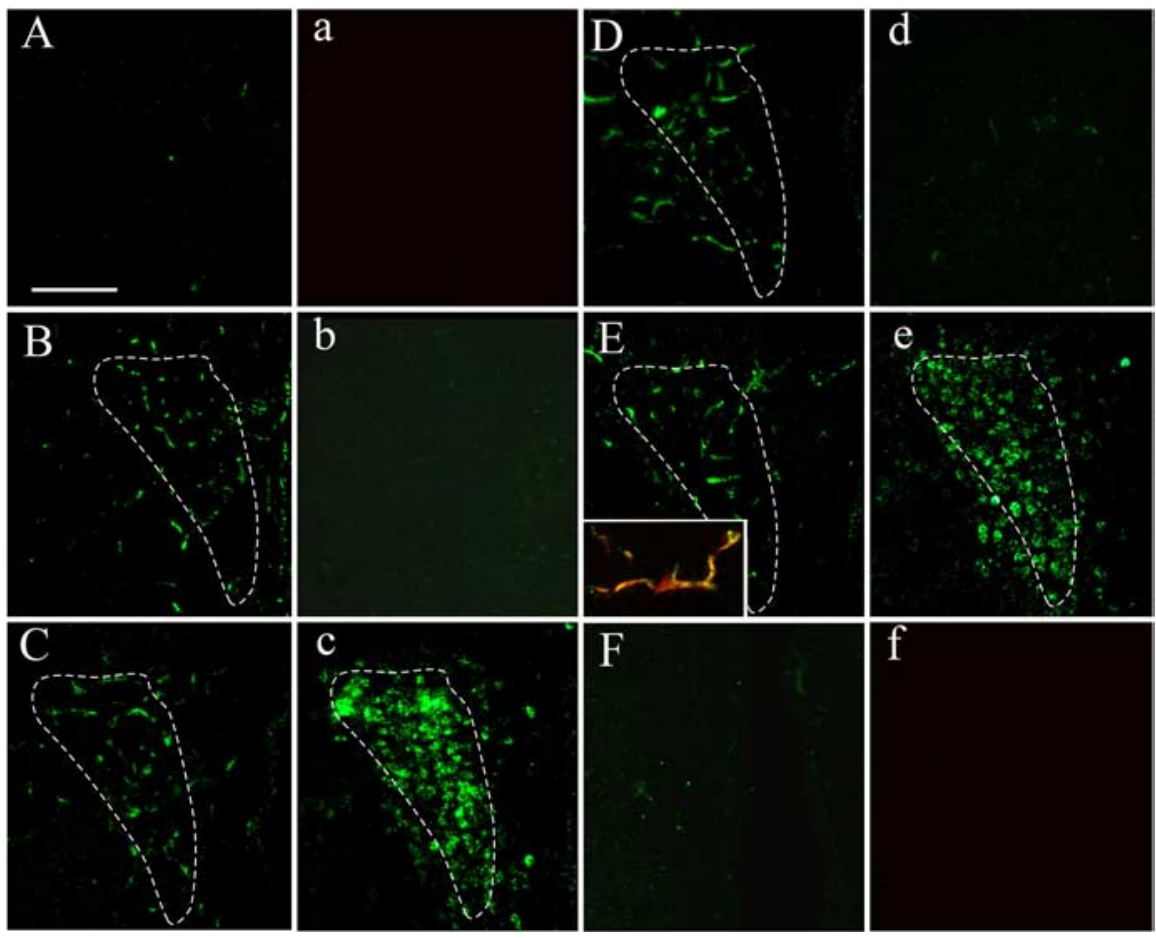

Figure 5. Representative IHC labeling of IL-1R1 and ISSH labeling of c-fos in the PVN. $\mathbf{A}-\mathbf{C}$, No IL-1R1 labeling was found in IL-1R1 knock-out mice $(\boldsymbol{A})$; IL-1R1 was detected in nontransgenic mice $2 \mathrm{~h}$ after intracerebroventricular injections of saline $(\boldsymbol{B})$ or IL-1 (20 ng/mouse) (C). D, E, IL-1R1 was also found in elL-1R1-water mice after intracerebroventricular injections of saline $(\boldsymbol{D})$ and IL-1 (E). $\boldsymbol{F}$, IL-1R1 was absent in elL-1R1-Dox mice after intracerebroventricular injections of saline (data not shown) and IL-1. The boundaries of PVN were indicated by the dashed line. The inset in $\boldsymbol{E}$ shows a high-magnification photograph of IL-1R1 (green)-and PECAM (red)-labeled cells. $\boldsymbol{a}$, ISSH labeling of c-fos was absent in the PVN of IL-1R1 knock-out mice after intracerebroventricular IL-1 injection. $\boldsymbol{b}, \boldsymbol{d}$, After intracerebroventricular saline injections, c-fos was absent in nontransgenic ( $\boldsymbol{b})$ and elL-1R1-water mice (d). c, e, Two hours after intracerebroventricular IL-1 injection, c-fos expression was induced in nontransgenic (c) and elL-1R1water mice $(\boldsymbol{e})$. $\boldsymbol{f}$, In elL-1R1-Dox mice, the induction of c-fos was absent after intracerebroventricular IL-1 injection. Scale bar, $100 \mu \mathrm{m}$.

P.M. on, both saline- and IL-1-injected animals showed similar nighttime temperature (data not shown). The nighttime temperature is higher than daytime temperature, probably because of heightened locomotor activity of this nocturnal animal. Concurrent with the change of body temperature, IL-1 injection resulted in a decrease in locomotor activity compared with saline-injected animals (Fig. 8C). In eIL-1R1-Dox animals, the body temperature (Fig. $8 \mathrm{~B}$ ) and activity (Fig. $8 \mathrm{D}$ ) responses to intracerebroventricular IL-1 were absent. Feeding Dox to both eIL-1R1-water and eIL-1R1-Dox animals did not induce statistically significant change in the activity and body temperature patterns recorded from previous days when they were fed with water (data not shown).

Figure 9 shows the temperature and activity changes induced after intraperitoneal IL-1 injection. In eIL-1R1-water animals, increase of body temperature was found $\sim 2.5 \mathrm{~h}$ after the injection. Peak temperature response was reached between 5 and $7 \mathrm{~h}$ after the injection (Fig. 9A). Concurrently, locomotor activity in IL-1-injected animals was decreased during the febrile response (Fig. 9C). IL-1 injection also induced febrile responses in eIL1R1-Dox animals, although significant increase of body temperature began $\sim 3.5 \mathrm{~h}$ after the IL- 1 injection (Fig. $9 \mathrm{~B}$ ). Concordant with the temperature change, IL-1 injection induced decreases in locomotor activity (Fig. 9D). The onset of febrile response was significantly delayed in eIL-1R1-Dox animals compared with that found in eIL-1R1-water animals $(209 \pm 38.6$ vs $139.4 \pm 23.8$ $\min ; p<0.05)$. Comparing to eIL-1R1-water animals, the overall febrile response in eIL-1-Dox animals was reduced (area under the curve during fever, $5.23 \pm 1.12$ vs $8.14 \pm 1.85 ; p<0.05)$.

Figure 10 shows the temperature and activity changes induced after intravenous IL-1 $(30 \mu \mathrm{g} / \mathrm{kg})$ injection. In eIL-1R1water animals, increase of body temperature was detected $30 \mathrm{~min}$ after the injection. Peak temperature response occurred between 90 and 120 min after the injection (Fig. 10A). This febrile response lasted for only $3.5 \mathrm{~h}$. Locomotor activities in these animals were also decreased during the febrile period (Fig. 10C). This intravenous IL-1-induced febrile response and reduced locomotor activity were absent in eIL1R1-Dox animals (Fig. 10 B,D). Injection of $3 \mu \mathrm{g} / \mathrm{kg}$ of IL-1 did not induce febrile response (data not shown) in normal or transgenic animals (data not shown).

To study the mechanism of IL-1induced effects, Cox-2 expression in the brain induced by IL-1 was studied. Figure 11 shows the results of Cox-2 labeling in the brain after intracerebroventricular, intraperitoneal, and intravenous injection of IL-1. These representative photographs were taken from the preoptic area. However, they are representative of the patterns in the entire brain because the observed Cox-2 induction was not regional specific, but highly associated with the vasculature. In Cox-2 knock-out animals, intracerebroventricular IL-1 injection did not induce Cox-2 expression in the brain (Fig. $11 A$ ), demonstrating the specificity of the IHC method used in this study. Four hours after intracerebroventricular injection of IL-1, Cox-2 was induced in numerous blood vessels in eIL-1R1-water animals (Fig. $11 \mathrm{~B}$, arrows) as well as in control nontransgenic animals (data not shown). No induction of Cox-2 was found in eIL-1R1-Dox animals (Fig. 11E). Four hours after intraperitoneal injection of IL-1, however, induction of Cox-2 was found only on sparse vessels of the brain endothelium in eIL-1R1-water animals (Fig. $11 C$, arrows), but not in eIL-1R1-Dox animals (similar to Fig. 11E) (data not shown). After intravenous injection of IL-1, Cox-2 was detected $2 \mathrm{~h}$ after the injection, again in sparsely distributed blood vessels of eIL-1R1-water animals (Fig. $11 \mathrm{D}$, arrows), but not in eIL-1R1Dox animals (Fig. $11 \mathrm{~F}$ ). Double-labeling results show that Cox-2 expression after all three routes of IL-1 administration colocalized with the endothelial marker PECAM (Fig. $11 B-D$, insets). Quantitative analysis of Cox-2 expression in eIL-1-R1-water and eIL-1R1-Dox mice after IL-1 injection is shown in Figure $11 G$. The number of Cox-2-labeled blood vessels was significantly reduced in eIL-1R1-Dox animals after either intracerebroventricular, intraperitoneal, or intravenous IL-1 injection.

Quantitative analysis of c-fos ISHH labeling in PVN (Fig. 12 A) and in VMPO (Fig. 12B) after intraperitoneal and intravenous injection of IL-1 are shown in Figure 12. Four hours after intraperitoneal IL-1 injection, c-fos expression was found in PVN proper (Fig. 12A) and in VMPO (Fig. 12B) in eIL-1R1-water animals. This effect was not significantly altered in eIL-1R1-Dox animals. Two hours after intravenous injection of IL-1, c-fos ex- 

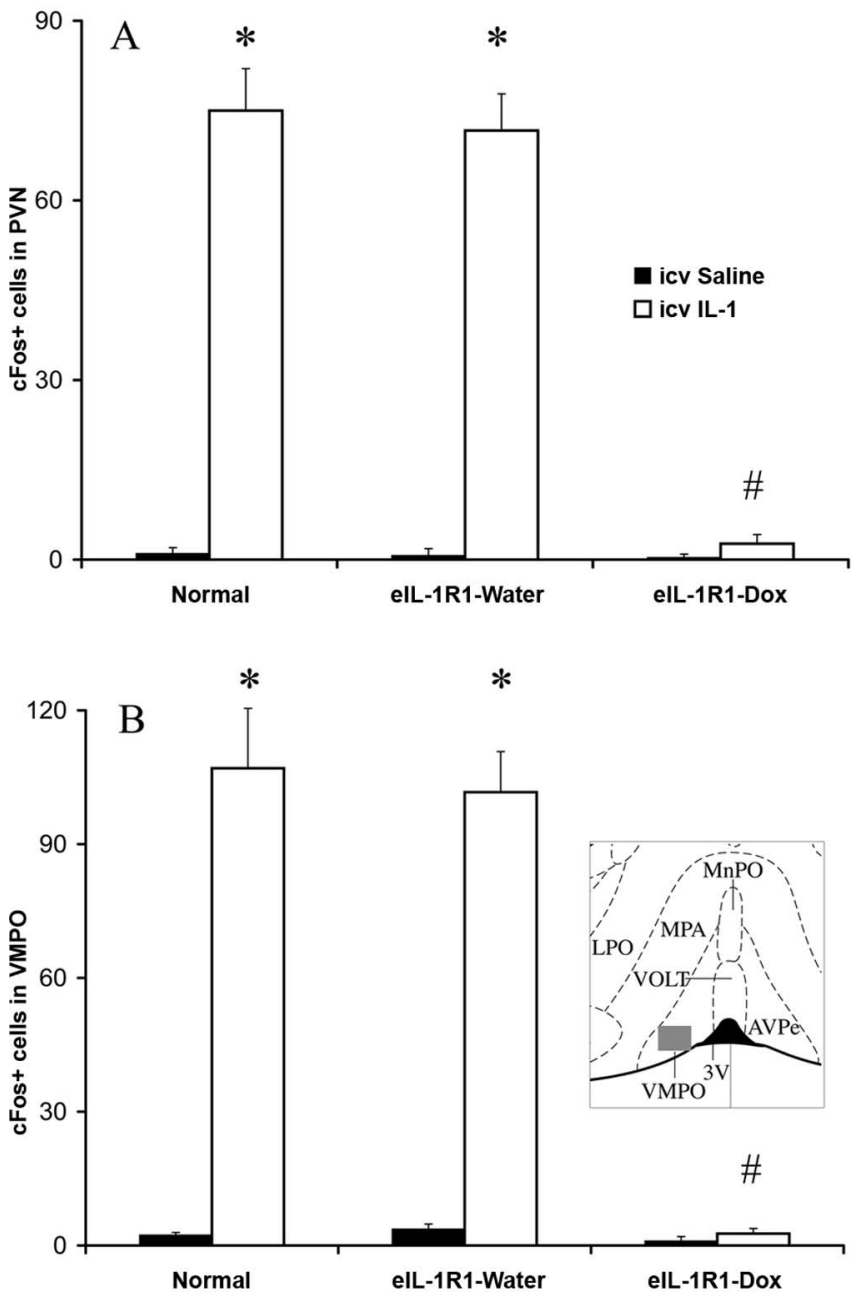

Figure 6. Quantitative analyses of ISHH labeling of c-fos-expressing cells in PVN $(\boldsymbol{A})$ and VMPO $(\boldsymbol{B})$ area of nontransgenic, elL-1R1-water, and elL-1R1-Dox mice $2 \mathrm{~h}$ after intracerebroventricular saline or IL-1 injection. Significant increases of $c$-fos-labeled cells were found in both PVN and VMPO after intracerebroventricular IL-1 injection in nontransgenic and in elL-1R1water animals, but was blunted in elL-1R1-Dox animals. Mean \pm SEM are shown $(n=$ $5 /$ group). The square in the inset in $\boldsymbol{B}$ indicates the region of quantification of c-fos-expressing cells in the VMPO. *Significant increase of c-fos-labeled cells $(p<0.05$, Student's $t$ test, saline vs IL-1). "Significant change of c-fos-labeled cells ( $p<0.05$, Student's t test, ell-1R1-water vs elL-1R1-Dox after IL-1 injection). MnP0, Median preoptic nucleus; MPA, medial preoptic area; $L P O$, lateral preoptic area; VOLT, vascular organ of the lamina terminalis; AVPe, anteroventral periventricular nucleus; $3 \mathrm{~V}$, third ventricle.

pression was again found in PVN (Fig. 12A) and VMPO (Fig. $12 B$ ) in eIL-1R1-water animals. In eIL-1R1-Dox animals, however, c-fos expression was blocked.

To exclude the possibility that Dox treatment blocked some of the effects induced by IL-1 because of the anti-inflammatory properties of Dox, we conducted a set of experiments with Doxtreated normal animals. Supplemental Figure 1 (available at www.jneurosci.org as supplemental material) shows that IL-1 injection-induced c-fos expression in the PVN and Cox-2 in brain parenchyma (quantified in VMPO region) were not blocked in Dox-treated normal animals, regardless of the routes of IL-1 injection. In addition, compared with saline-injected animals, intracerebroventricular, intraperitoneal, and intravenous IL-1 all induced significant febrile response and reduced locomotor activity (supplemental Fig. 2, available at www.jneurosci.org as supplemental material).
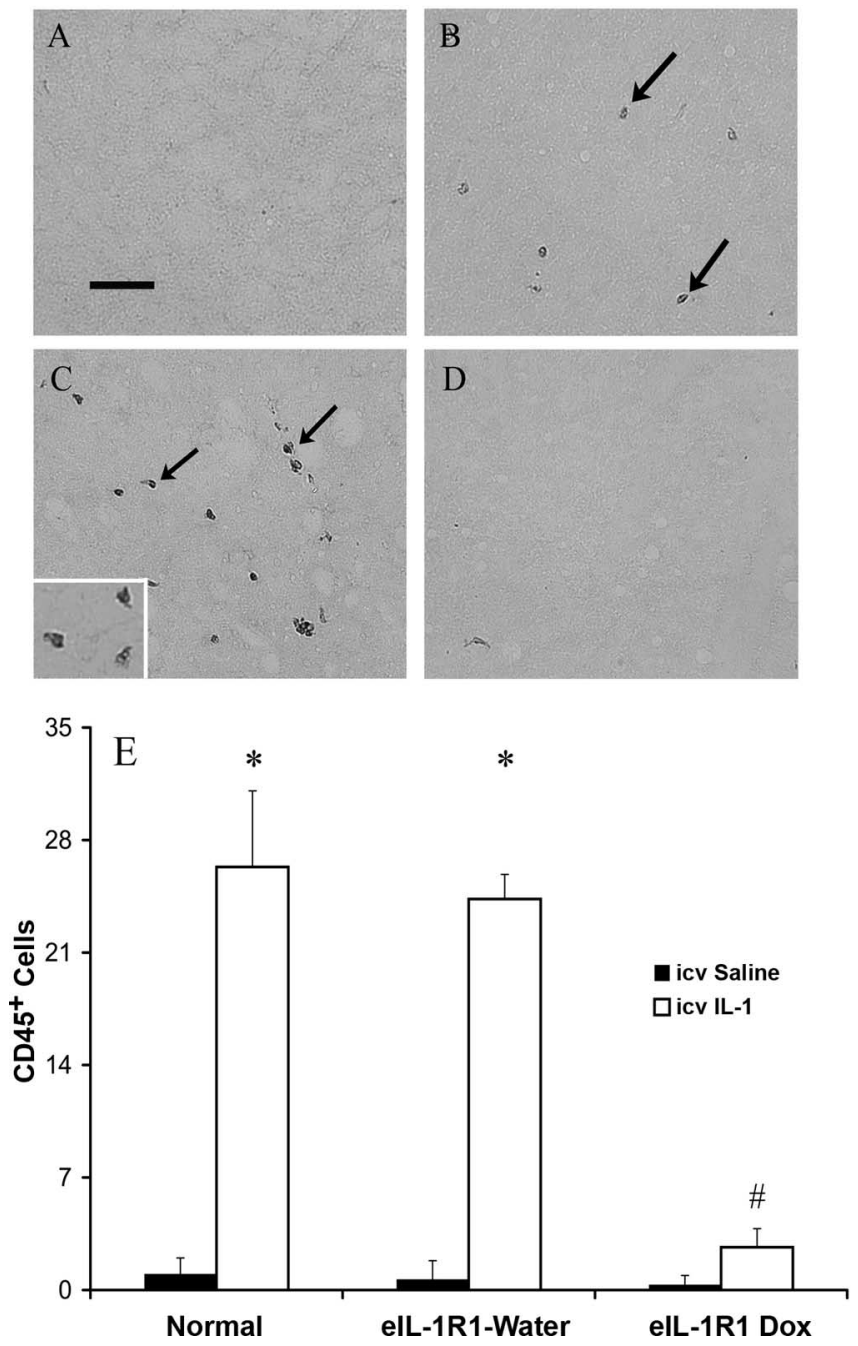

Figure 7. Representative microphotographs of $C D 45$ labeling in brain parenchyma. The arrows in $\boldsymbol{B}$ and $\boldsymbol{C}$ point to $C D 45^{+}$cells. Scale bar: (in $\left.\boldsymbol{A}\right) \boldsymbol{A}-\boldsymbol{D}, 100 \mu \mathrm{m} . \boldsymbol{A}, \mathrm{N}_{0}$ CD $45^{+}$cells were found in normal saline-injected animals. $\boldsymbol{B}, \boldsymbol{C}$, Widespread appearance of $\mathrm{CD} 45^{+}$cells was found $16 \mathrm{~h}$ after intracerebroventricular IL-1 injection in the brain parenchyma of nontransgenic $(B)$ and ell-1R1-water $(\boldsymbol{C})$ animals. The presence of $\mathrm{CD}^{+} 5^{+}$cells in the brain parenchyma of elL-1R1-Dox was absent after IL-1 injection. The inset in C shows a high-magnification picture of $\mathrm{CD} 45^{+}$cells. E, Quantitative analysis of the number of $\mathrm{CD} 45^{+}$cells. Mean \pm SEM are shown ( $n=5 /$ group). * Significant increase of CD45-labeled cells ( $p<0.05$, Student's $t$ test, saline vs IL-1). "Significant change of CD45-labeled cells ( $p<0.05$, Student's $t$ test, elL-1R1-water vs elL-1R1-Dox after IL-1 injection).

\section{Discussion}

The results of the present study show that we successfully created an endothelial IL-1R1 knockdown model. In this model, Dox treatment induced uniform and universal expression of EGFP in endothelial cells. Concomitant with the expression of EGFP, IL1R1 expression on endothelial cells was inhibited. In addition, we showed that the IL-1R1 knockdown was restricted to endothelial cells. As a consequence of eIL-1R1 blockade, a salient functional outcome of central IL-1 injection, the recruitment of leukocytes into brain parenchyma was prevented. And finally, central IL-1 induced neuronal activation in the brain of eIL-1R1-water mice, but not in eIL-1R1-Dox mice.

This strain of transgenic mice was not perfect in controlling IL-R1 expression on endothelial cells. Leaky transcription was observed in transgenic animals without Dox treatment. The leaky transcription of EGFP and presumably antisense IL-1R1 were 

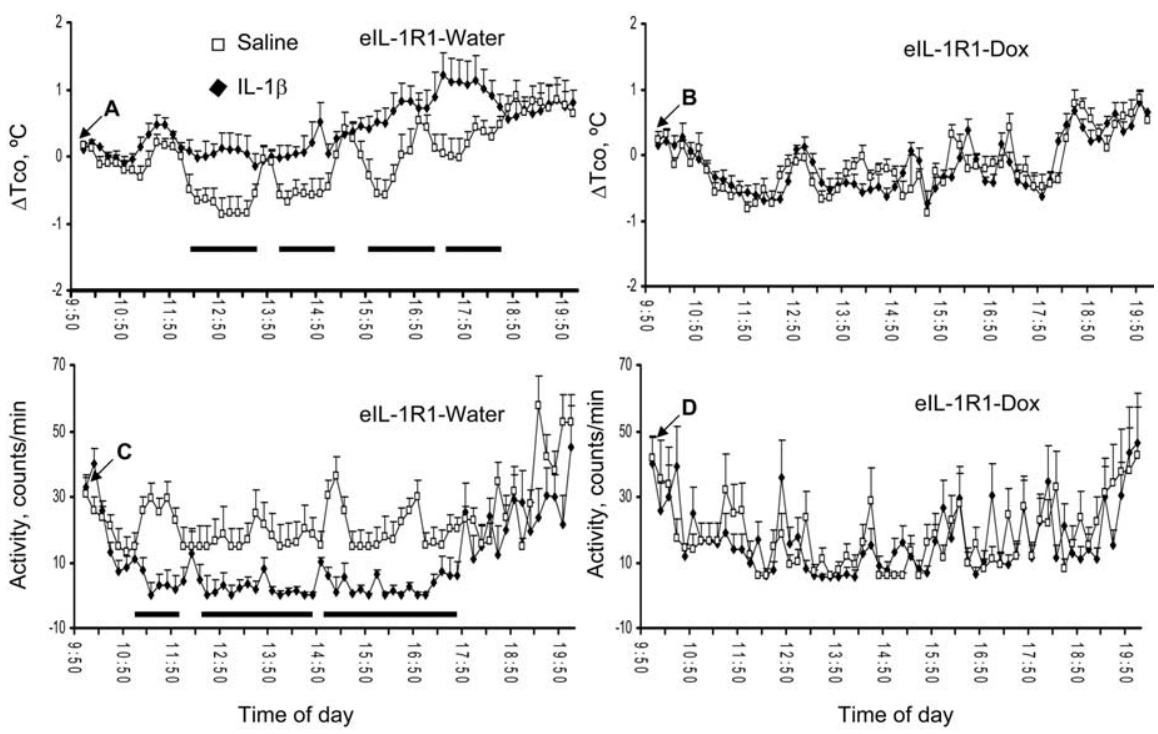

Figure 8. Changes in core body temperature $\left(\Delta \mathrm{Tco},{ }^{\circ} \mathrm{C}\right)$ and activity counts (counts/min) in elL-1R1-water and elL-1R1-Dox animals that received intracerebroventricular injection of saline or IL-1 $\beta(20 \mathrm{ng} / \mathrm{mouse})$ are shown. Mean \pm SEM are shown $(n=$ 5/group). The injections were always made at 10:00 A.M. (arrow). Time periods in which significant differences were detected between saline-injected and IL-1-injected animals are marked by black bars $(p<0.05)$. The $x$-axis depicts time of the day.
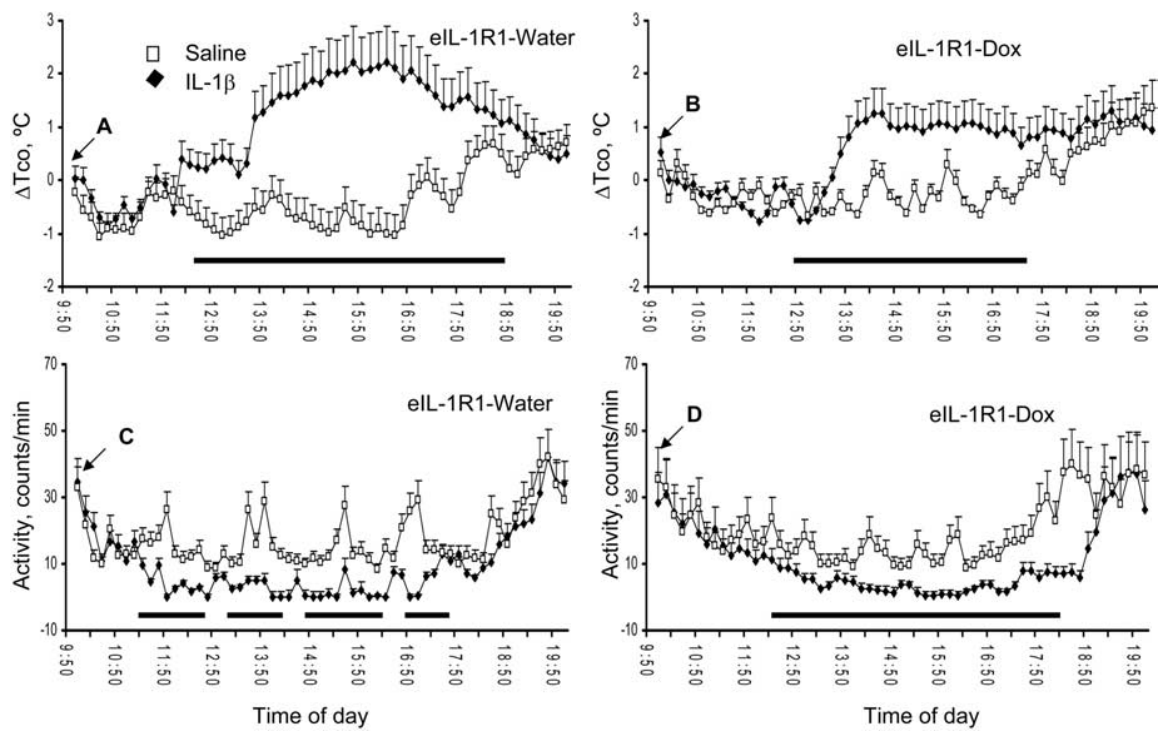

Figure 9. Changes in core body temperature $\left(\Delta \mathrm{Tco},{ }^{\circ} \mathrm{C}\right)$ and activity counts (counts/min) in elL-1R1-water and elL-1R1-Dox animals that received intraperitoneal injection of saline or IL-1 $\beta(25 \mu \mathrm{g} / \mathrm{kg})$ are shown. Mean $\pm \mathrm{SEM}$ are shown ( $n=5 / \mathrm{group})$.

only found in sparse endothelial cells. This is probably caused by cointegration of the driver and responder transgenes in close vicinity in the genome (Teng et al., 2002). As shown in Figure 5, endothelial expression of IL-1R1 was not detectably altered in transgenic animals without Dox treatment. In addition, central IL-1-induced infiltration of leukocytes as well as c-fos expression in the PVN was not altered in transgenic animals with leaky transcription of EGFP. Thus, significant conditional endothelial knockdown of IL-1R1 was achieved only after animals were fed with Dox. Another concern is that Dox-treated animals appear to exhibited lower locomotor activity after saline injection. Dox treatment alone, however, did not block various IL-1-induced effects (supplemental Figs. 1, 2, available at www. jneurosci.org as supplemental material).

The blockade of all the examined intracerebroventricular IL-1 effects in eIL-1R1-Dox mice was mostly expected. This is because in the brain IL$1 \mathrm{R} 1$ is predominantly expressed in endothelial cells (Cunningham and De Souza, 1993; Ericsson et al., 1995), and many central effects of IL-1, such as fever (Cao et al., 1996), sickness behavior (Nadjar et al., 2005), and activation of the hypothalamic-pituitary-adrenal axis (Parsadaniantz et al., 2000), were linked with its ability to stimulate the expression of Cox-2 in brain endothelial cells.

What was quite unexpected was that endothelial-specific knockdown of IL-1R1 was not able to abolish intraperitoneal IL1 -induced fever, decrease of locomotor activity, and c-fos expression in the hypothalamus. This is not attributable to the possibility that higher activity of IL-1 may be achieved near cerebral blood vessels after intraperitoneal IL-1 administration, because the intraperitoneal IL-1 did not induce more c-fos (Fig. 12) and Cox-2 (Fig. 11) expression in the brain than those induced by the intracerebroventricular and intravenous IL-1 injections. The results suggest that locally released IL-1 in the peritoneal cavity activates CNS via a pathway independent of IL-1R1 on endothelial cells. This scenario is consistent with previous studies that showed that locally released IL-1 can activate CNS directly via neural pathways. Thus, a large literature exists supporting the theory that vagal afferents mediate various illness behaviors induced by peripheral immune challenge (Maier et al., 1998). In addition, febrile responses induced by local inflammation can be blocked by local anesthetic applied to the site of infection (Roth and De Souza, 2001). Therefore, vagus nerve and/or primary sensory nerve may relay peripheral inflammation to the CNS, bypassing brain endothelium. The present study demonstrates that these neural pathways may be dissociated from the brain endothelial IL-1R1 system. It should be noted, however, that whether vagal afferents alone are sufficient to mediate fever induced by IL- 1 is still controversial. Recent studies showed that vagotomy blocked fever induced by low doses, but not high doses, of IL-1 (Hansen et al., 2001). In another study, febrile responses to even low doses of intraperitoneal IL-1 could not be blocked by vagotomy (Luheshi et al., 2000). The present results (obtained from intraperitoneal injection of a high dose of IL-1) cannot resolve this controversy, but support the concept that neural transmission of peripheral IL-1 signaling may at least partially mediate the febrile response.

The present study also sheds light on the issue of Cox-2 in mediating peripheral IL-1 induced CNS activation. Peripheral IL-1 induced fever is absent in Cox-2 knock-out animals ( Li et al., 2001). Therefore, induction of Cox-2 expression is considered a necessary downstream event that mediates peripheral IL-1induced fever. The critical location of Cox-2 expression involved 
in the CNS activation, however, has not been determined. Cao et al. (1996) suggested that the expression of Cox-2 in brain endothelial cells mediates peripheral IL-1 signal to the brain because the level of endothelial Cox-2 expression can be correlated with febrile responses. This is further supported by recent studies that showed intravenous IL-1 induced Cox-2 expression primarily on brain endothelial cells (Lacroix and Rivest, 1998; Proescholdt et al., 2002). The present result that both CNS activation and Cox-2 expression in brain endothelial cells induced by intravenous IL-1 can be blocked by endothelialspecific knockdown of IL-1R1 demonstrates that circulating IL-1 indeed engages IL-1R1 on cerebral endothelium to stimulate Cox-2 expression.

It should be noted that, under certain conditions, intravenous IL-1-induced Cox-2 expression has been identified in
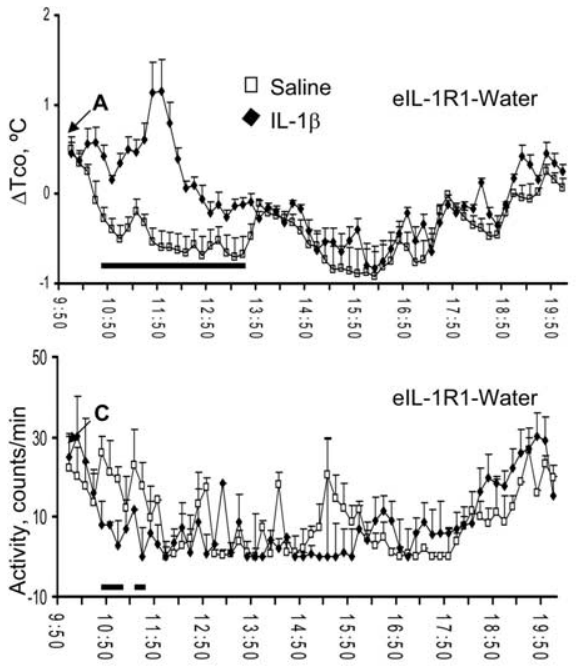

Time of day
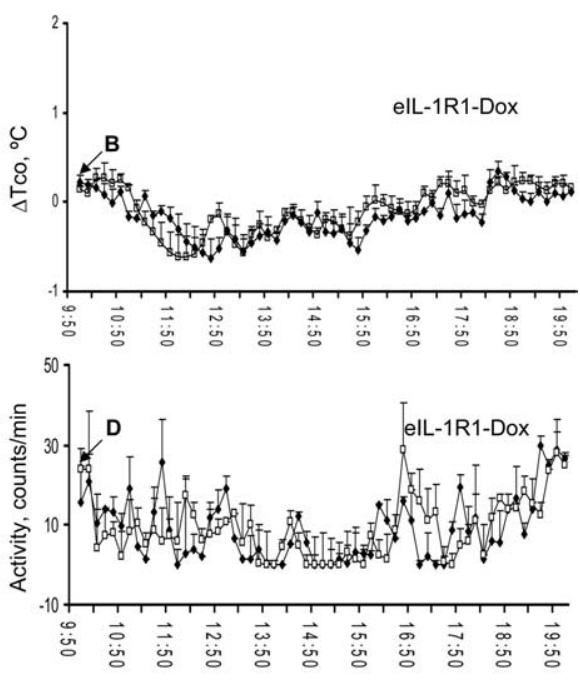

Time of day

Figure 10. Changes in core body temperature $\left(\Delta \mathrm{Tc} 0,{ }^{\circ} \mathrm{C}\right)$ and activity counts (counts/min) in elL-1R1-water and elL-1R1-Dox animals that received intravenous injection of saline or IL-1 $\beta(30 \mu \mathrm{g} / \mathrm{kg})$ are shown. Mean \pm SEM are shown ( $n=7 /$ group). the brain in perivascular monocytes

(Elmquist et al., 1997; Schiltz and Sawchenko, 2002) in rats. Under the conditions of the present study, the induced expression of Cox-2 has been identified in endothelial cells in mice, consistent with the results that eIL-1R1 knockdown blocked intravenous IL-1-induced activation of CNS. It is possible that, under conditions in which intravenous IL-1 primarily stimulates the expression of Cox-2 on perivascular monocytes, the activation of CNS may no longer require the presence of endothelial IL-1R1.

An important point that can be made from the present results is that the induction of brain endothelial Cox-2 expression is not necessary for peripheral local IL-1-induced CNS activation because intraperitoneal IL-1 activated CNS in eIL-1R1-Dox animals despite that the induction of Cox- 2 in their brain endothelium was blunted. This result suggests that IL-1R1 and Cox-2 expressed in nonendothelial cells can mediate peripheral IL-1induced activation of CNS. The nonendothelial IL-1R1 and Cox-2 may be especially important for neural transmission of peripheral IL-1 activity. Recent studies showed that, along the potential neural pathways of neuroimmune communication, nonendothelial IL-1R1 and Cox-2 may play important roles. Thus, Rummel et al. (2005) showed that the production of prostaglandin $\mathrm{E}_{2}$ at the site of local inflammation is critical for the induction of fever, and Samad et al. (2001) showed spinal neuronal expression of Cox-2 and IL-1R1 relay signals from localized peripheral inflammation to the brain via ascending sensory nerve tracts. Therefore, CNS activation via these neural pathways would still depend on the expression of Cox-2 and IL-1R1, although endothelial expression of IL-1R1 and Cox-2 may not be involved. This notion is further reinforced by the present results that, although intracerebroventricular IL-1 apparently induced more Cox-2 expression in brain endothelial cells than that induced by intraperitoneal IL-1 (Fig. 11), febrile responses induced by intracerebroventricular IL-1 were not larger than those induced by intraperitoneal IL-1.

A counterintuitive point that requires explanation is that one might assume that the neural pathway should mediate the early, not the late phase of the fever, yet eIL-1R1 knockdown appears to block the early phase of the intraperitoneal IL-1 fever. It is possible, however, that IL-1 administered in the peritoneal cavity needs to stimulate intermediates to activate the ascending nerve pathways, thereby activating the eIL-1R1 independent neural pathways at the later stage of the fever. Therefore, the neural pathways activated by intraperitoneal IL-1 may contribute to the late phase of the fever.

It is important to point out that intravenous injection of IL-1 results in the presence of IL-1 in circulation. Although this manipulation produces a model by which the effects of circulating IL-1 can be studied, IL-1 was rarely detected in the blood of febrile patients (Chen et al., 1995; Strait et al., 1999). Therefore, under most pathophysiological conditions, circulating IL-1 is not likely the mediator of neuroimmune communication.

Previous studies have suggested that IL-6 may mediate IL-1induced activation of CNS (Kozak et al., 1998). The crucial role of circulating IL-6 in mediating peripheral local inflammationinduced fever and Cox-2 expression in brain endothelial cells has been demonstrated recently. Rummel et al. (2006) showed that injection of a specific antiserum against IL- 6 blocked local inflammation-induced fever and brain endothelial Cox-2 expression. The present results that CNS activation induced by intravenous and intracerebroventricular IL-1 can be blocked by endothelial IL-1R1 deletion suggests that either endothelial IL-1R1 plays an important role in IL-1-induced IL-6 expression, or alternatively, endothelial IL-1R1 may play a part in CNS activation that is independent of IL-6.

In summary, this study demonstrates a powerful tool to study neuroimmune communication at the blood-brain barrier. The present results demonstrate that the neuroimmune actions of central IL- 1 are mediated by endothelial IL-1R1 and probably the consequent production of Cox-2 in these cells. Peripheral local IL-1, however, can employ other mechanisms, probably via ascending sensory nervous systems to activate CNS neurons and elicit illness symptoms without requiring the action of central IL-1. In addition, circulating IL-1 may act primarily on endothelial IL-1R1 in the brain to trigger CNS responses.

\section{References}

Akaneya Y, Takahashi M, Hatanaka H (1995) Interleukin-1 beta enhances survival and interleukin-6 protects against MPP + neurotoxicity in cultures of fetal rat dopaminergic neurons. Exp Neurol 136:44-52.

Berkenbosch F, van Oers J, del Rey A, Tilders F, Besedovsky H (1987) 

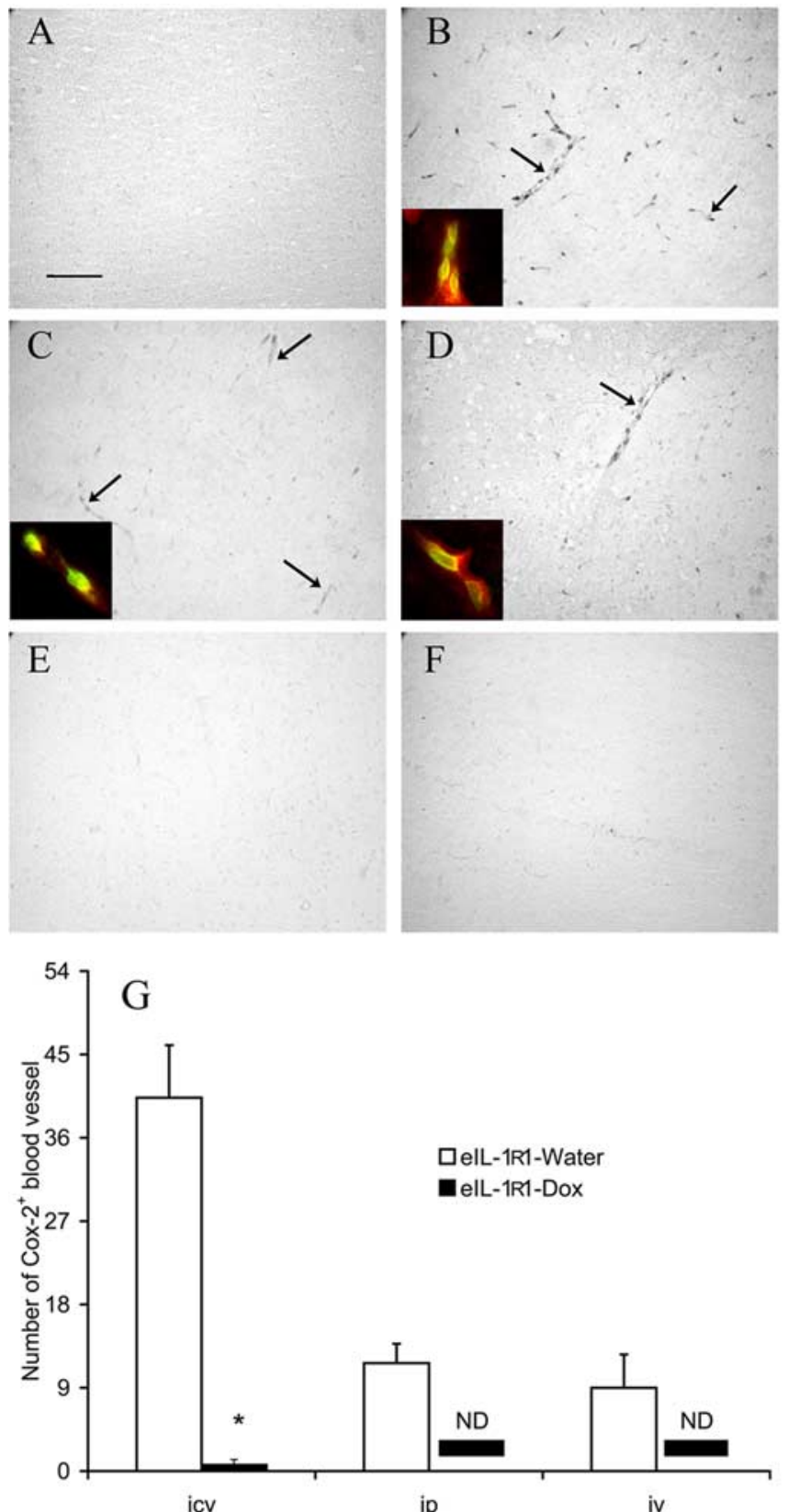

Figure 11. Representative microphotographs showing Cox-2 IHC labeling in the preoptic area of the hypothalamus. The arrows point to example Cox-2 labeling on blood vessels. $\boldsymbol{A}, \boldsymbol{B}$, Induction of Cox-2 was found in ell-1R1-water mice $(\boldsymbol{B}) 4 \mathrm{~h}$ after intracerebroventricular IL-1 injection but not in Cox-2 knock-out mice (A). C, D, Much less Cox-2 labeling was found after intraperitoneal ( $4 \mathrm{~h}$ after injection; $\boldsymbol{C}$ ) and intravenous ( $2 \mathrm{~h}$ after injection; $\boldsymbol{D}$ ) IL-1 injection. $\boldsymbol{E}, \boldsymbol{F}$, Cox-2 labeling was not detected in the brain of ell-1R1-Dox animals after intracerebroventricular $(\boldsymbol{E})$, intraperitoneal (data not shown), and intravenous $(\boldsymbol{F})$ IL-1 injection. Double labeling of Cox-2 with PECAM shows colocalization of Cox-2 and PECAM after all three routes of IL-1 administration (insets in $\boldsymbol{B}-\boldsymbol{D}$ ). Scale bar, $100 \mu \mathrm{m}$. $\mathbf{G}$, Quantitative analysis of the number of Cox-2-expressing blood vessels in elL-1-R1-water and elL-1R1-Dox mice after three different routes of IL- 1 injection. Mean \pm SEM are shown ( $n=5 /$ group). The number of Cox-2-labeled blood vessels was significantly reduced in elL-1R1-Dox animals after intracerebroventricular IL-1 injection. * Significant decrease of Cox-2-labeled blood vessels ( $p<0.05$, Student's $t$ test, elL-1R1-water vs elL-1R1-Dox). After intraperitoneal and intravenous IL-1 injection, Cox-2labeled blood vessels were not detected in ell-1R1-Dox animals. ND, Not detected.

Corticotropin-releasing factor-producing neurons in the rat activated by interleukin-1. Science 238:524-526.

Brady LS, Lynn AB, Herkenham M, Gottesfeld Z (1994) Systemic
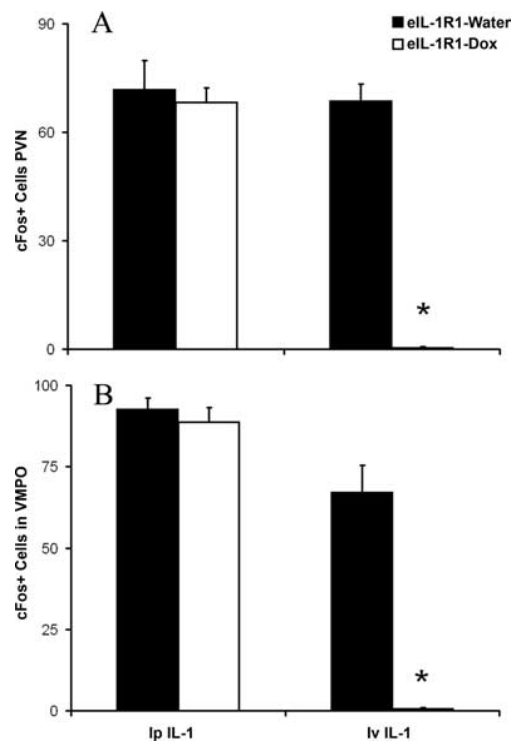

Figure 12. Quantitative analyses of ISHH labeling of c-fos-expressing cells in PVN and VMPO. Induction of c-fos was found in the PVN of ell-1R1-water mice $4 \mathrm{~h}$ after intraperitoneal and $2 \mathrm{~h}$ after intravenous IL-1 injection and in elL-1R1-Dox mice $4 \mathrm{~h}$ after intraperitoneal IL-1 injection. $A$, Induction of $\mathrm{c}-$ fos was absent in the PVN of elL-1R1-Dox mice $2 \mathrm{~h}$ after intravenous IL-1 injection. Similarly, induction of c-fos was found in VMP0 of ell-1R1-water mice after intraperitoneal and intravenous IL-1 injections and elL-1 R1-Dox mice after intraperitoneal IL-1 injection. $B$, Induction of c-fos was absent in VMPO in elL-1R1-Dox mice after intravenous IL-1 injection. *Significant decrease of c-fos-expressing cells after intravenous IL-1 injections ( $p<0.05$, Student's $t$ test, elL-1R1-water vs elL-1R1-Dox).

interleukin- 1 induces early and late patterns of c-fos mRNA expression in brain. J Neurosci 14:4951-4964.

Breder CD, Saper CB (1996) Expression of inducible cyclooxygenase mRNA in the mouse brain after systemic administration of bacterial lipopolysaccharide. Brain Res 713:64-69.

Cao C, Matsumura K, Yamagata K, Watanabe Y (1996) Endothelial cells of the rat brain vasculature express cyclooxygenase- 2 mRNA in response to systemic interleukin-1 beta: a possible site of prostaglandin synthesis responsible for fever. Brain Res 733:263-272.

Chen YM, Whang-Peng J, Chern CH, Kuo BI, Wang SY, Perng RP (1995) Elevation of serum IL-6 levels in patients with acute bacterial infection. Zhonghua Yi Xue Za Zhi (Taipei) 56:239-243.

Ching S, He L, Lai W, Quan N (2005) IL-1 type I receptor plays a key role in mediating the recruitment of leukocytes into the central nervous system. Brain Behav Immun 19:127-137.

Cunningham ETJ, De Souza EB (1993) Interleukin 1 receptors in the brain and endocrine tissues. Immunol Today 14:171-176.

Das S, Potter H (1995) Expression of the Alzheimer amyloid-promoting factor antichymotrypsin is induced in human astrocytes by IL-1. Neuron 14:447-456.

Elmquist JK, Breder CD, Sherin JE, Scammell TE, Hickey WF, Dewitt D, Saper CB (1997) Intravenous lipopolysaccharide induces cyclooxygenase 2-like immunoreactivity in rat brain perivascular microglia and meningeal macrophages. J Comp Neurol 381:119-129.

Ericsson A, Liu C, Hart RP, Sawchenko PE (1995) Type 1 interleukin-1 receptor in the rat brain: distribution, regulation, and relationship to sites of IL-1-induced cellular activation. J Comp Neurol 361:681-698.

Hansen MK, O'Connor KA, Goehler LE, Watkins LR, Maier SF (2001) The contribution of the vagus nerve in interleukin- $1 \beta$-induced fever is dependent on dose. Am J Physiol Regul Integr Comp Physiol 280:R929-R934.

Konsman JP, Vigues S, Mackerlova L, Bristow A, Blomqvist A (2004) Rat brain vascular distribution of interleukin-1 type-1 receptor immunoreactivity: relationship to patterns of inducible cyclooxygenase expression by peripheral inflammatory stimuli. J Comp Neurol 472:113-129.

Kozak W, Kluger MJ, Soszynski D, Conn CA, Rudolph K, Leon LR, Zheng H (1998) IL-6 and IL-1 beta in fever. Studies using cytokine-deficient (knockout) mice. Ann NY Acad Sci 856:33-47.

Lacroix S, Rivest S (1998) Effect of acute systemic inflammatory response 
and cytokines on the transcription of the genes encoding cyclooxygenase enzymes (COX-1 and COX-2) in the rat brain. J Neurochem 70:452-466.

Li S, Ballou LR, Morham SG, Blatteis CM (2001) Cyclooxygenase-2 mediates the febrile response of mice to interleukin-1beta. Brain Res 910:163-173.

Li Y, Liu L, Barger SW, Griffin WS (2003) Interleukin-1 mediates pathological effects of microglia on tau phosphorylation and on synaptophysin synthesis in cortical neurons through a p38-MAPK pathway. J Neurosci 23:1605-1611.

Luheshi GN, Bluthe RM, Rushforth D, Mulcahy N, Konsman JP, Goldbach M, Dantzer R (2000) Vagotomy attenuates the behavioural but not the pyrogenic effects of interleukin-1 in rats. Auton Neurosci 85:127-132.

Lynch MA (2002) Interleukin-1 beta exerts a myriad of effects in the brain and in particular in the hippocampus: analysis of some of these actions. Vitam Horm 64:185-219.

Maier SF, Goehler LE, Fleshner M, Watkins LR (1998) The role of the vagus nerve in cytokine-to-brain communication. Ann NY Acad Sci 840:289-300.

Nadjar A, Bluthe RM, May MJ, Dantzer R, Parnet P (2005) Inactivation of the cerebral NFkappaB pathway inhibits interleukin-1beta-induced sickness behavior and c-Fos expression in various brain nuclei. Neuropsychopharmacology 30:1492-1499.

Parsadaniantz SM, Lebeau A, Duval P, Grimaldi B, Terlain B, Kerdelhue B (2000) Effects of the inhibition of cyclo-oxygenase 1 or 2 or 5-lipoxygenase on the activation of the hypothalamic-pituitary-adrenal axis induced by interleukin-1beta in the male rat. J Neuroendocrinol 12:766-773.

Proescholdt MG, Chakravarty S, Foster JA, Foti SB, Briley EM, Herkenham M (2002) Intracerebroventricular but not intravenous interleukin-1beta induces widespread vascular-mediated leukocyte infiltration and immune signal mRNA expression followed by brain-wide glial activation. Neuroscience 112:731-749.

Quan N, Herkenham M (2002) Connecting cytokines and brain: a review of current issues. Histol Histopathol 17:273-288.

Quan N, Whiteside M, Herkenham M (1998) Cyclooxygenase 2 mRNA expression in rat brain after peripheral injection of lipopolysaccharide. Brain Res 802:189-197.
Quan N, He L, Lai W (2003) Endothelial activation is an intermediate step for peripheral lipopolysaccharide induced activation of paraventricular nucleus. Brain Res Bull 59:447-452.

Roth J, De Souza GE (2001) Fever induction pathways: evidence from responses to systemic or local cytokine formation. Braz J Med Biol Res 34:301-314.

Rummel C, Barth SW, Voss T, Korte S, Gerstberger R, Hubschle T, Roth J (2005) Localized vs. systemic inflammation in guinea pigs: a role for prostaglandins at distinct points of the fever induction pathways? Am J Physiol 289:R340-R347.

Rummel C, Sachot C, Poole S, Luheshi GN (2006) Circulating interleukin-6 induces fever through a STAT3-linked activation of COX-2 in the brain. Am J Physiol 291:R1316-R1326.

Samad TA, Moore KA, Sapirstein A, Billet S, Allchorne A, Poole S, Bonventre JV, Woolf CJ (2001) Interleukin-1beta-mediated induction of Cox-2 in the CNS contributes to inflammatory pain hypersensitivity. Nature 410:471-475.

Sapolsky R, Rivier C, Yamamoto G, Plotsky P, Vale W (1987) Interleukin-1 stimulates the secretion of hypothalamic corticotropin-releasing factor. Science 238:522-524.

Schiltz JC, Sawchenko PE (2002) Distinct brain vascular cell types manifest inducible cyclooxygenase expression as a function of the strength and nature of immune insults. J Neurosci 22:5606-5618.

Schlaeger TM, Bartunkova S, Lawitts JA, Teichmann G, Risau W, Deutsch U, Sato TN (1997) Uniform vascular-endothelial-cell-specific gene expression in both embryonic and adult transgenic mice. Proc Natl Acad Sci USA 94:3058-3063.

Strait RT, Kelly KJ, Kurup VP (1999) Tumor necrosis factor-alpha, interleukin-1 beta, and interleukin-6 levels in febrile, young children with and without occult bacteremia. Pediatrics 104:1321-1326.

Teng PI, Dichiara MR, Komuves LG, Abe K, Quertermous T, Topper JN (2002) Inducible and selective transgene expression in murine vascular endothelium. Physiol Genomics 11:99-107.

Zhang J, Rivest S (2000) A functional analysis of EP4 receptor-expressing neurons in mediating the action of prostaglandin E2 within specific nuclei of the brain in response to circulating interleukin-1beta. J Neurochem $74: 2134-2145$. 